\title{
Contrasting responses of the coral Acropora tenuis to moderate and strong light limitation in coastal waters
}

\author{
Julia Strahl ${ }^{\mathrm{a}, \mathrm{b}, *}$, Melissa M. Rocker ${ }^{\mathrm{c}}$, Katharina E. Fabricius ${ }^{\mathrm{c}}$ \\ ${ }^{a}$ Helmholtz Institute for Functional Marine Biodiversity at the University of Oldenburg, Ammerländer Heerstraße 231, 23129, Oldenburg, Germany \\ ${ }^{\mathrm{b}}$ Institute of Biology and Environmental Sciences, Carl von Ossietzky University Oldenburg, Carl von Ossietzky Str. 9-11, 26111, Oldenburg, Germany \\ ${ }^{\mathrm{c}}$ Australian Institute of Marine Science, PMB \#3, Townsville MC, QLD, 4810, Australia
}

\section{A R T I C L E I N F O}

\section{Keywords:}

Coral health

Physiological performance

Great Barrier Reef

Light attenuation

Photosynthesis

Calcification

Respiration

\begin{abstract}
A B S T R A C T
Coastal water quality and light attenuation can detrimentally affect coral health. This study investigated the effects of light limitation and reduced water quality on the physiological performance of the coral Acropora tenuis. Branches of individual colonies were collected in $2 \mathrm{~m}$ water depth at six inshore reefs at increasing distances from major river sources in the Great Barrier Reef, along a strong water quality gradient in the Burdekin and a weak gradient in the Whitsunday region. Rates of net photosynthesis, dark respiration, and light and dark calcification were determined at daily light integrals (DLI) of moderate (13.86-16.38 mol photons $\mathrm{m}^{-2}$ $\left.\mathrm{d}^{-1}\right)$, low (7.92-9.36 mol photons $\left.\mathrm{m}^{-2} \mathrm{~d}^{-1}\right)$ and no light $\left(0 \mathrm{~mol}\right.$ photons $\left.\mathrm{m}^{-2} \mathrm{~d}^{-1}\right)$, in both the dry season (October 2013, June 2014) and the wet season (February 2014). Along the strong but not the weak water quality gradient, rates of net photosynthesis, dark respiration and light calcification increased towards the river mouth both in the dry and the wet seasons. Additionally, a 50\% light reduction (from moderate to low light), as often found in shallow turbid waters in the Burdekin region, reduced rates of net photosynthesis and light calcification by up to $70 \%$ and $50 \%$. The data show the acclimation potential in $A$. tenuis to river derived nutrients and sediments at moderate DLI (i.e., in very shallow water). However, prolonged and frequent periods of low DLI (i.e., in deeper water, especially after high river sediment discharges) will affect the corals' energy balance, and may represent a major factor limiting the depth distribution of these corals in turbid coastal reefs.
\end{abstract}

\section{Introduction}

A warming climate from rising greenhouse gas emissions does not only increase the frequency of coral bleaching events, but also the storm intensity and rainfall variability in many tropical regions (Fuessel, 2009; Lough, 2011). In north-eastern Australia, increasing rainfall variability, in conjunction with the expansion of agriculture, clearing of vegetation, and intensified grazing and fertiliser application has led to increasing river discharges of sediments, nutrients and pollutants into the Great Barrier Reef (GBR) since European settlement (approx. 1870 AD) (McCulloch et al., 2003). Along the coast of Queensland, more than 30 major rivers discharge suspended sediments, dissolved and particulate organic and inorganic nutrients into the GBR, especially during monsoonal floods in the wet season (Schaffelke et al., 2012; Thompson et al., 2014a). As a consequence, coastal water quality in the GBR has been classified as relatively poor in the last decades (Thompson et al., 2014a).
Species-specific abilities for acclimatisation determine how much mature corals are affected by water quality related pressures. Corals can be stressed by suspended sediments and particulate matter, which increase water turbidity and limit light availability for autotrophic (light driven) energy production (Anthony and Connolly, 2004; BessellBrowne et al., 2017a), whereas deposited sediments may smother corals and interfere with heterotrophic feeding (Erftemeijer et al., 2012; Weber et al., 2012). A low capacity for photoacclimation -physiological plasticity that optimizes photosynthesis under different light intensities (Bradshaw, 1965; Schlichting, 1986) -can lead to reduced photosynthesis, a negative energy balance and reduced growth and survival in corals (Bessell-Browne et al., 2017a, b, Richmond, 1993). In the Florida Keys, corals are functioning close to a compensation point where respiration equals photosynthesis and little energy remains for growth in areas with decreasing water transparency (Yentsch et al., 2002). In Goniastrea retiformis, daily respiration exceeded daily photosynthesis after two months of experimental shading by suspended

\footnotetext{
* Corresponding author. Helmholtz-Institute for Functional Marine Biodiversity at the University of Oldenburg, Ammerländer Heerstrasse 231, 26129, Oldenburg, Germany.

E-mail address: julia.strahl@hifmb.de (J. Strahl).
} 
particulate matter (Anthony and Fabricius, 2000). And three corals Acropora palmata, Diploria strigosa and Montastrea annularis showed decreasing net photosynthesis during experimental exposure to sediments, attributable to shading and increasing respiration rates during sediment removal (Abdel-Salam and Porter, 1988). The efficiency of sediment rejection depends on growth form, mucus production and ciliary action, and greatly differ between species (Abdel-Salam and Porter, 1988; Stafford-Smith, 1993). Similarly, photo- and heterotrophic plasticity - the potential to acclimatize and switch from autotrophy to heterotrophy in turbid water - are highly species-specific (Anthony and Fabricius, 2000; Grottoli et al., 2004). In G. retiformis, increasing rates of suspended particle feeding compensated fully for the $35-47 \%$ lower phototrophy after 2 months of experimental shading, while in Porites cylindrica a lack of photo- and heterotrophic plasticity resulted in energy deficiencies (e.g. decline in tissue mass and lipid contents; Anthony and Fabricius, 2000). And two species of temperature-stressed corals (Stylophora pistillata and Galaxea fascicularis) maintained higher photosynthetic efficiency and cell division rates of algal endosymbionts (mitotic index) when well-fed rather than experimentally starved (Ferrier-Pagès et al., 2010). While some experimental studies suggest that higher energy reserves and increasing heterotrophic feeding in nutrient rich coastal waters might increase the resilience of corals to environmental stressors (reviewed in Fabricius et al., 2013a), field studies show increasing incidence of coral disease and bleaching (Pollock et al., 2014; Wiedenmann et al., 2012) in nutrient- and suspended sediment-rich and light limited environments. A model suggests that corals exposed to nutrient-rich coastal waters in the GBR may have had a decreased bleaching resistance (per degree of heating) during the 1998 and 2002 mass bleaching events compared to reefs in oligotrophic oceanic waters, effectively lowering the upper thermal bleaching threshold by $1.0-1.5^{\circ} \mathrm{C}$ (Wooldridge and Done, 2009).

In the Burdekin and Whitsunday regions, exposure to high turbidity, nutrients and sedimentation, have clearly selected for coral species tolerant of these conditions (Thompson et al., 2014a). Palaeoecological evidence and recent investigations suggest a shift in coral communities in the Burdekin region from communities dominated by arborescent Acropora species to remnant communities dominated by non-Acropora species due to a sustained decline in water quality (Roff et al., 2013, Thompson et al., 2014a, b). Corals of the genus Acropora are typically classified as highly susceptible to bleaching and diseases, with a low capacity of individuals to recover from environmental stressors (Loya et al., 2001; Marshall and Baird, 2000). However, Acropora tenuis occurs in high abundances on inshore reefs, and its lipid contents were significantly higher at inshore compared to offshore reefs (Anthony, 2006), suggesting a high potential to cope with nutrient exposure in this particular Acropora species. Similarly, when supplied experimentally with suspended particulate matter, Acropora intermedia had reduced bleaching susceptibility and increased survival rates (Anthony et al., 2007). These studies demonstrate the inconsistency in the literature on the sensitivity of Acropora spec. to decreasing water quality.

The aim of this study was to determine whether light limitation and changing water quality affects or benefits physiological processes in $A$. tenuis along a strong and a weak water quality gradient in the inshore GBR. Corals were investigated in the dry and the wet season in the Burdekin and the Whitsunday regions each with 3 reefs of differing exposure to a river source. In order to estimate the effect of light attenuation on the physiological performance of these corals, rates of net photosynthesis, dark respiration, and light and dark calcification of live A. tenuis were determined in field-based incubation experiments at moderate, low, and no light (13.86-16.38, 7.92-9.36 and 0 mol photons $\mathrm{m}^{-2} \mathrm{~d}^{-1}$ ).

\section{Materials and methods}

\subsection{Study sites}

The study was conducted at six inshore reefs in the central sector of the GBR, along a strong water quality gradient in the Burdekin region and a weak water quality gradient in the Whitsunday region, in conjunction with the study of Rocker et al. (2017). These reefs are regularly monitored for environmental and ecological parameters (Thompson et al., 2014a) by the Australian Institute of Marine Science (AIMS) as part of the long-term Inshore Marine Monitoring Program (MMP). Land use in the dry tropical Burdekin catchment is dominated by cattle grazing and irrigated sugarcane cultivation (Brodie et al., 2003). The Burdekin River contributes the highest loads of suspended sediments to the GBR lagoon (Bainbridge et al., 2012; Brodie et al., 2003). The study reefs Pelorus $\left(\mathrm{S} 18^{\circ} 32.435^{\prime}\right.$ E146 $\left.29.326^{\prime}\right)$, Pandora (S18 $48.980^{\prime}$ $\left.\mathrm{E} 146^{\circ} 26.059^{\prime}\right)$ and Magnetic Island (S19 $\left.09.264^{\prime} \mathrm{E} 146^{\circ} 52.083^{\prime}\right)$ are located approximately $125 \mathrm{~km}, 115 \mathrm{~km}$ and $60 \mathrm{~km}$ from the river mouth, the latter with high levels of turbidity of up to 8 NTU (long term mean $=2.15$ NTU; Fabricius et al., 2013a). The more southerly Whitsunday Region, with significantly elevated nutrient loads, comprises four smaller adjacent river catchments (Proserpine, O'Connell, Pioneer, Plane) dominated by agriculture (e.g. cropping and grazing; Schaffelke et al., 2012) and widespread fertiliser use (Brodie et al., 2003). The reefs Double Cone (S20 06.281' E148 ${ }^{\circ} 43.298^{\prime}$ ), Daydream (S20 $15.343^{\prime}$ $\left.\mathrm{E} 148^{\circ} 48.749^{\prime}\right)$ and Pine Island (S20 $22.685^{\prime}$ E148 $\left.53.311^{\prime}\right)$ are located $50 \mathrm{~km}, 30 \mathrm{~km}$ and $20 \mathrm{~km}$ away from the nearest river.

Samples of sea water at the six study sites were regularly collected and analysed by AIMS as part of the long-term MMP. To characterise water quality conditions in February (Austral summer, wet season), June (Austral winter, early dry season) and October (Austral spring, late dry season), samples from 2007 to 2014 were averaged to determine typical temperature, salinity and dissolved organic, inorganic nutrients and particulates and Secchi depth (Table 1) as described in Thompson et al. (2014a). The monthly average irradiances (mol photons $\mathrm{m}^{-2} \mathrm{~s}^{-1}$ ) at $2 \mathrm{~m}$ and $5 \mathrm{~m}$ depth for each site were calculated using Beer - Lambert's Law:

$\mathrm{E}_{\mathrm{z}}=\mathrm{E}_{0} \times \mathrm{e}^{-\mathrm{kd} * \mathrm{z}}$

where $E_{z}$ is photosynthetically active radiation (PAR) at a given depth, $E_{0}$ is surface PAR, kd is the light attenuation coefficient and $z$ is depth in meters. The light attenuation coefficient was calculated for each site and month using Secchi depth measurements $\left(\mathrm{z}_{\mathrm{d}}\right)$ taken from Thompson et al. (2014a):

$\mathrm{kd}=1.7 / \mathrm{z}_{\mathrm{d}}$

Data of monthly average surface PAR in February $(524 \mu \mathrm{mol}$ photons $\left.\mathrm{m}^{-2} \mathrm{~s}^{-1}\right)$, June $\left(401 \mu \mathrm{mol}\right.$ photons $\left.\mathrm{m}^{-2} \mathrm{~s}^{-1}\right)$ and October 2007-2014 $\left(629 \mu \mathrm{mol}\right.$ photons $\left.\mathrm{m}^{-2} \mathrm{~s}^{-1}\right)$ were obtained from the AIMS weather station at Cleveland Bay (http://weather.aims.gov.au/\#/ station/3). Calculated irradiances at $2 \mathrm{~m}$ and $5 \mathrm{~m}\left(\mathrm{E}_{2 \mathrm{~m}}\right.$ and $\left.\mathrm{E}_{5 \mathrm{~m}}\right)$ were transformed into monthly average daily light integrals (DLI, mol photons $\mathrm{m}^{-2} \mathrm{~d}^{-1}$ ).

Mean DLI at $2 \mathrm{~m}$ depth varied between 18 and $22 \mathrm{~mol}_{\text {photons }} \mathrm{m}^{-2}$ $\mathrm{d}^{-1}$ at Magnetic Island, which was on average 18-48\% lower compared to Pelorus and Pandora in the three sampling months (Table 1). In contrast, reefs in the Whitsundays showed similar DLI at $2 \mathrm{~m}$ depth in June and October, and only in February, DLI were on average 18\% lower at Pine compared to Double Cone and Daydream. Furthermore, DLI declined from $2 \mathrm{~m}$ to $5 \mathrm{~m}$ water depth on average by $47 \%$ at Pelorus and Pandora and by $64-69 \%$ at the Whitsunday reefs and Magnetic Island.

Spatial and temporal patterns in the other water quality and physical parameters at the six study sites in February, June and October 2007-2014 have been characterised with principle component analysis 


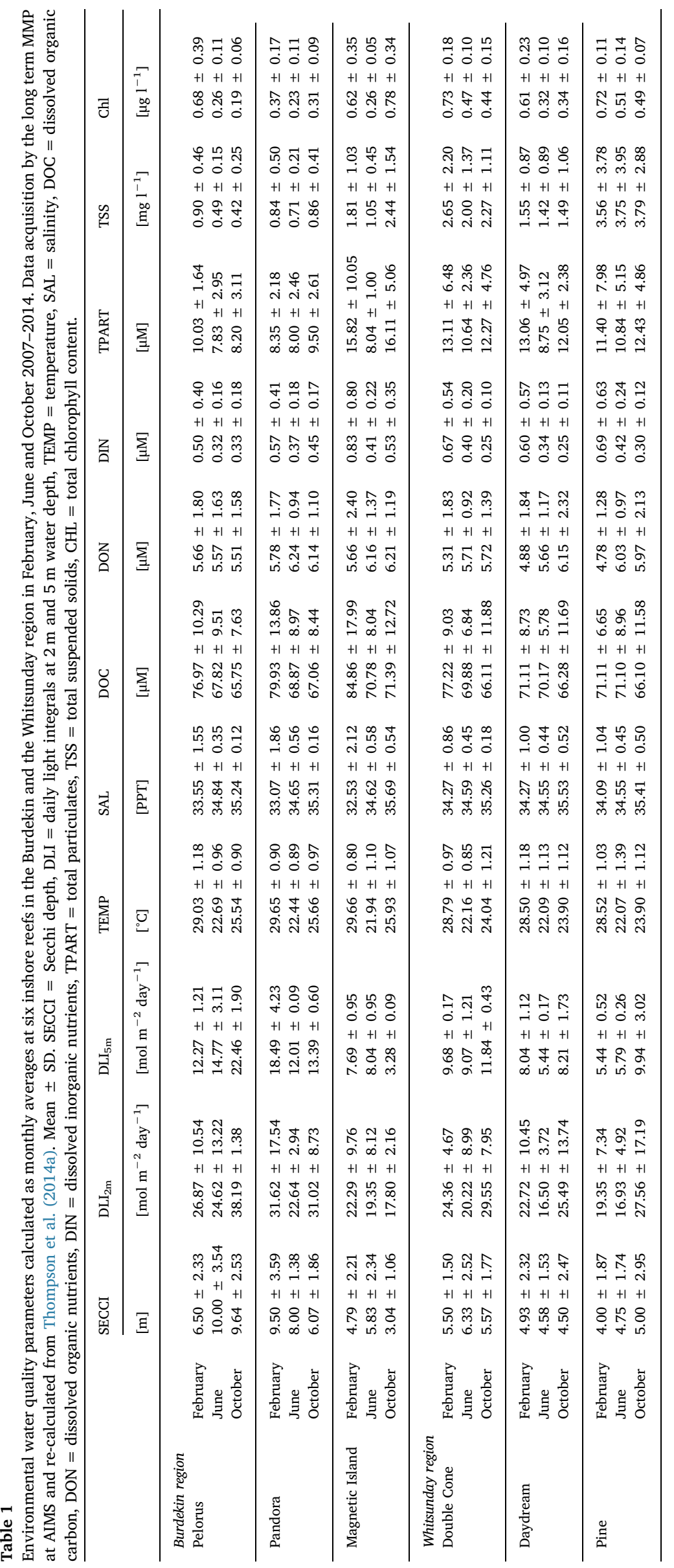


(PCA) and generalised linear models (GLMs) by Rocker et al. (2017). At all reefs, sea water temperatures were highest in February and lowest in June (Table 1). At most reefs, distinctly higher values of dissolved inorganic nutrients and chlorophyll $a$ were measured in February compared to June and October, while total particulates were lowest in June (Table 1). At the Burdekin reefs, salinity was consistently lower and dissolved organic carbon higher in February compared to the other months. The six inshore reefs were best differentiated in the wet season (February) (see PCA and GLM results, Rocker et al., 2017). High values of particulates, dissolved organic carbon, dissolved inorganic nutrients and low salinity separated Burdekin reefs and ordered them according to decreasing distance from the river source and coast. In comparison, the reef separation in the Whitsundays was not as strong (Fabricius et al., 2013b; Rocker et al., 2017; Thompson et al., 2014a). For example, concentrations of total suspended solids were up to five times higher at Magnetic Island than Pelorus $\left(2.44 \pm 1.54 \mathrm{mg}^{-1}\right.$ versus $0.42 \pm 0.25 \mathrm{mg} \mathrm{l}^{-1}$ ) compared to the Whitsunday reefs with higher variation (e.g. $3.79 \pm 2.88$ versus $2.27 \pm 1.11 \mathrm{mgl}^{-1}$, Table 1 ). In the latter, all three reefs were described by high temperature and particulates in February (Rocker et al., 2017, Table 1). Secchi depth and calculated irradiances at $2 \mathrm{~m}$ and $5 \mathrm{~m}$ water depths were considerably higher, while total particulates and total suspended solids were lower at Pelorus and Pandora compared to all other sites (Table 1).

As described in Rocker et al. (2017), fragments of 12-20 individual Acropora tenuis colonies $\left(\sim 15 \times 15 \mathrm{~cm}^{2}\right)$ were collected at each of the six reefs at depths of 1-3 $\mathrm{m}$. To facilitate multiple sampling, the fragments were attached to a stainless steel rack $\sim 0.5 \mathrm{~m}$ above the substrate at each reef following Howells et al. (2013). Racks were located in $2 \mathrm{~m}$ water depth in close proximity $(\leq 10 \mathrm{~m})$ to the MMP water sampling sites where environmental parameters are monitored regularly (Thompson et al., 2014a). The racks were established in October 2012 at all reefs except Daydream and Double Cone, which were established in February and June 2013 for logistical reasons (Rocker et al., 2017).

\subsection{Physiological measurements in corals}

To determine rates of net photosynthesis, dark respiration and net calcification, one branch $(5-6 \mathrm{~cm}$ in height) per colony was collected from 10 to 12 of these A. tenuis fragments per reef in October 2013, February 2014 and June 2014. The branches were transported to the RV Cape Ferguson in partitioned, perforated plastic boxes, and kept continuously submerged in temperature controlled sea water during transport and experimentation. Seawater for the incubation experiments was collected at the respective sampling sites in large buckets.

The 10 to 12 replicate branches per reef were incubated in the light and in the dark under controlled conditions on the ship deck of the RV Cape Ferguson following the protocol of Strahl et al. (2015). Branches were transferred into bins with seawater sourced from their site of origin, and placed upright (kept in place with a plastic screw) into the lids of custom-made, inverted clear acryl incubation chambers with a water volume of $0.635 \mathrm{~L}$ (Fig. 1C). The chambers were placed onto submersible stands (Fig. 1A and B) in black flow-through bins acting as water baths to keep the temperature constant according to seasonal field conditions. The stands contained motor units and pullies (Fig. 1A and $\mathrm{B}$ ) to continuously mix the seawater in each chamber by a magnetic stir bar to minimize boundary layer thickness. Incubations were conducted under controlled light (AI Sol White LED Modules, Clear choice, Los Angeles, USA) at either 350 or $200 \mu \mathrm{mol}$ photons $\mathrm{m}^{-2} \mathrm{~s}^{-1}$, equivalent to moderate DLI of $16.38,13.86$ and 15,12 mol photons $\mathrm{m}^{-2}$ $\mathrm{d}^{-1}$ or low DLI of 9.36, 7.92 and 8.64 mol photons $\mathrm{m}^{-2} \mathrm{~d}^{-1}$ at 11,12 and $13 \mathrm{~h}$ of illumination in February, June and October, similar to values recorded at the most turbid reefs in the Burdekin and Whitsunday region between $2 \mathrm{~m}$ and $5 \mathrm{~m}$ depth (Table 1 ). For a better resolution of the effect of light attenuation on physiological performance of $A$. tenuis along the strong water quality gradient, incubation experiments were run at both moderate and low DLI (13.86-16.38 and 7.92-9.36 mol photons $\mathrm{m}^{-2} \mathrm{~d}^{-1}$ ) in the Burdekin region, while corals in the Whitsunday region were investigated at moderate DLI $(13.86-16.38 \mathrm{~mol}$ photons $\mathrm{m}^{-2} \mathrm{~d}^{-1}$ ) exclusively. After approximately $2 \mathrm{~h}$ of incubation under controlled light, the chambers were opened, and the oxygen concentration $\left(\mathrm{O}_{2}\right)$ of each chamber was analysed with a hand-held dissolved oxygen meter (HQ30d, equipped with LDO101 IntelliCAL oxygen probe, Hach, USA). The accuracy of using final $\mathrm{O}_{2}$ readings with the Hach oxygen meter was confirmed in a previous study by Strahl et al. (2015). Subsamples of seawater with a volume of $0.05 \mathrm{~L}$ were taken from each incubation chamber for the determination of total alkalinity $\left(A_{T}\right)$. To minimize the effect of light enhanced respiration, the corals were pre-incubated in the dark for $0.5 \mathrm{~h}$. Then, the chambers containing the corals were again filled with fresh seawater from the respective sampling sites and closed, keeping the corals submerged at all times. Dark incubations were conducted with the bins covered with black lids, and the seawater samples from each chamber analysed for $A_{T}$ and $\mathrm{O}_{2}$ after $3 \mathrm{~h}$ incubation. During each light and dark incubation run, two chambers without corals were used as blanks to provide information on potential changes in $\mathrm{A}_{\mathrm{T}}$ and $\mathrm{O}_{2}$ due to the metabolic activity of microorganisms (e.g., plankton and bacteria) in the seawater. Subsequent to the dark incubations, coral branches were snap-frozen in liquid nitrogen to determine surface area and pigment content. Light and dark calcification rates of the incubated corals were determined with the alkalinity anomaly technique (Chisholm and Gattuso, 1991). Rates of net photosynthesis, dark respiration, and light and dark calcification were standardised to surface area and incubation time, and calculated in $\mathrm{mg} \mathrm{O}_{2} \mathrm{~cm}^{-2} \mathrm{~h}^{-1}$ and $\mu \mathrm{M} \mathrm{C} \mathrm{cm}{ }^{-2} \mathrm{~h}^{-1}$ after subtracting the values measured in the blank chambers. Net calcification was calculated in $\mu \mathrm{M} \mathrm{C} \mathrm{cm}^{-2} 24 \mathrm{~h}^{-1}$ assuming $12 \mathrm{~h}$ and $12 \mathrm{~h}$ (of day and night time, respectively) in October, $13 \mathrm{~h}$ and $11 \mathrm{~h}$ in February and $11 \mathrm{~h}$ and $13 \mathrm{~h}$ in June.

\subsection{Surface area and pigment content determination}

Coral tissue was removed from the skeleton with an air gun in $10 \mathrm{~mL}$ of ultra-filtered seawater $(0.05 \mu \mathrm{m})$, and the homogenate was separated into host and Symbiodinium fractions by centrifugation ( $3 \mathrm{~min}, 1500 \times \mathrm{g}$, $4{ }^{\circ} \mathrm{C}$ ). Skeletons were dried overnight in the oven at $60^{\circ} \mathrm{C}$ and the surface area was determined using the single wax dipping technique (Veal et al., 2010).

Contents of chlorophyll $a$ and $b$ of the Symbiodinium fraction were determined spectrophotometrically following a modified protocol of Lichtenthaler (1987) and Ritchie (2008). The Symbiodinium fraction was suspended in ethanol 95\%, sonicated on ice (15 s, 40\% amplitude, Sonic-Vibra Cell, John Morris Scientific), incubated on ice for $20 \mathrm{~min}$ and centrifuged for $5 \mathrm{~min}$ at $4{ }^{\circ} \mathrm{C}$ and $10,000 \times g$. The absorbencies of the supernatant containing the pigments were recorded in a Synergy $\mathrm{H} 4$ Hybrid Reader spectrophotometer (BioTek, USA) at 664 and $649 \mathrm{~nm}$. The total chlorophyll ( = chlorophyll $a+\mathrm{b}$ ) content was calculated with equations of Lichtenthaler (1987) and standardised to surface area.

\subsection{Statistical analysis}

Statistical analyses were conducted with R (Version 2.15.3, R Core Team 2015). The Burdekin and the Whitsunday region were analysed separately due to geographical (e.g. one big versus four small river catchments; $65-125 \mathrm{~km}$ versus $20-50 \mathrm{~km}$ distance from the river mouths) and environmental differences (e.g. different spatial and temporal patterns in DLI, water quality and physical parameters result in strong versus weak water quality gradient). Generalised linear models (GLM) and ANOVA were used to assess the effect of light, sampling time ( = month), reef, on rates of net photosynthesis, dark respiration, light, dark and net calcification, and pigment content using the $\mathrm{R}$ package stats $\quad(\mathrm{GLM}=$ Burdekin net photosynthesis and light and net 

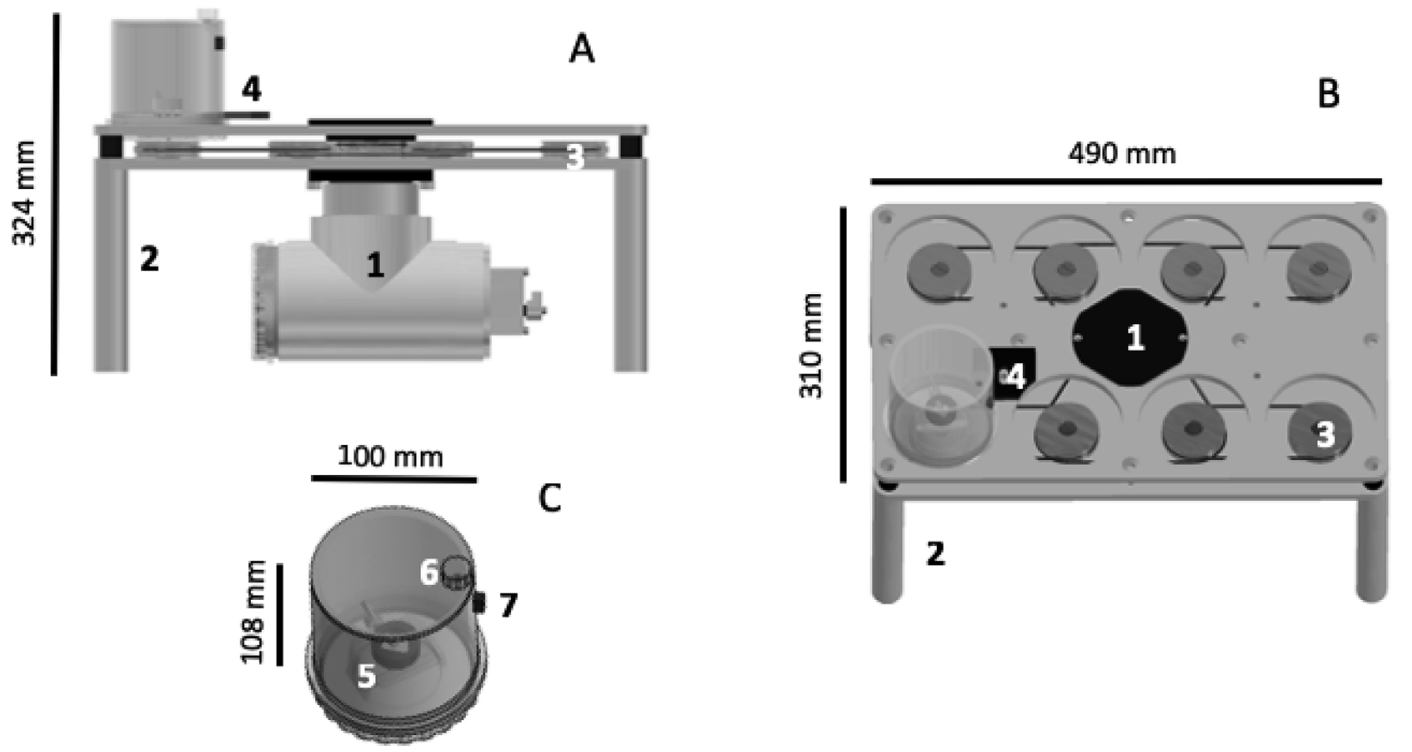

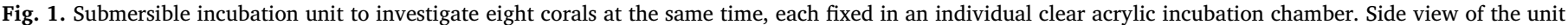

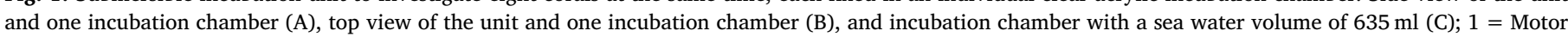

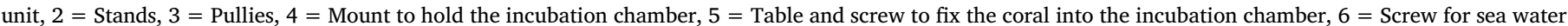
release, $7=$ Mounting to hold the glass-fibre cable for oxygen sensing.

calcification; ANOVA = all remaining data sets). The three explanatory factors in the models - light, month and reef - were treated as fixed factors. The distribution pattern of each data was tested with a Kolmogorov-Smirnov test, resulting in a Gaussion distribution pattern. Net photosynthesis and light and net calcification of corals in the Burdekin region fitted the model best after a square root transformation.

\section{Results}

\subsection{Burdekin region}

Typically, net photosynthesis, dark respiration rates and total chlorophyll content increased from reefs with low turbidity to high turbid reefs, and tended to increase with sea water temperature (Figs. 2A and B \& 3). At moderate DLI, corals displayed 13-76\% higher photosynthesis rates at Magnetic Island compared to Pelorus and Pandora in all months (Table 2, Fig. 2A). Similarly, dark respiration rates were significantly higher (24-31\%) at Magnetic Island compared to Pelorus in all three months, and compared to Pandora in February and June (20-26\%) (Table 2, Fig. 2B). In all three months, total chlorophyll content was higher at Magnetic Island than at Pelorus (56-85\%) and Pandora (31-50\%) (Table 2, Fig. 3). Net photosynthesis at moderate DLI was significantly higher at Magnetic Island (31\%), Pandora (42\%) and Pelorus (63\%) in February ( $=$ the warmest month) compared to October and June (Fig. 2A). Also, total chlorophyll content was highest in February at all three reefs (Fig. 3), while dark respiration was 14-40\% lower in June compared to October and February (Fig. 2B).

Importantly, net photosynthesis rates in corals from the Burdekin region significantly decreased with experimental light (Table 2). At Pelorus and Magnetic Island, net photosynthesis significantly declined (50-69\%) at low compared to moderate DLI during all sampling months. At Pandora, net photosynthesis decreased by $18-24 \%$ in October and February and by $66 \%$ in June (Fig. 2A).

Similar to observations in net photosynthesis and dark respiration, calcification tended to increase from low to high turbid reefs (Table 3, Fig. 2C and D). In February and June, dark calcification as well as light and net calcification at moderate DLI were significantly higher (28-55\%) at Magnetic Island compared to less turbid reefs (Tables 2 and 3, Fig. 2C and D). Net calcification rates at Magnetic Island and Pelorus were highest in February and at Pandora in October (Table 3).

In most cases, light and net calcification declined with light (Table 3, Fig. 2C). At low compared to moderate DLI, light and net light calcification rates decreased significantly at Magnetic Island in February $(42 \%$ and $32 \%)$ and June (24\% and $17 \%)$, and at Pelorus in October (49\% and 40\%) and February (37\% and 27\%) (Tables 2 and 3, Fig. 2C).

\subsection{Whitsunday region}

Concurrent to findings for the Burdekin region, net photosynthesis rates in A. tenuis at moderate DLI significantly increased in the warmest month at all three reefs in the Whitsunday region (Table 4). At Double Cone, values were $10 \%$ and $55 \%$ higher in February than in October and June, at Daydream 59\% and $26 \%$ and at Pine $45 \%$ and $27 \%$ (Fig. 4A). Contrasting to the Burdekin region, no clear reef related pattern could be detected for net photosynthesis and dark respiration in corals of the Whitsundays (Table 4). At Double Cone, dark respiration was $24 \%$ lower in June compared to October and February, at Daydream $4-15 \%$ and at Pine 25-29\%, however differences between months were not significant (Fig. 4B). The total chlorophyll content displayed a significant interaction between month and reef (Table 4). At all three reefs in the Whitsunday region, the total chlorophyll content in A. tenuis was $50-62 \%$ lower in October than in February and June, but values were higher at Double Cone than at the other two reefs in all months (Table 4, Fig. 3). Light, dark and calculated net calcification rates remained unaffected by reef and months (Tables 3 and 4; Fig. 4C and D).

\section{Discussion}

\subsection{Physiological variability in corals along a strong and a weak water quality gradient}

A high level of physiological acclimation was detected in A. tenuis along the relatively strong water quality gradient in the Burdekin region, with decreasing rates of net photosynthesis, dark respiration and light and net calcification with increasing distance from the river 

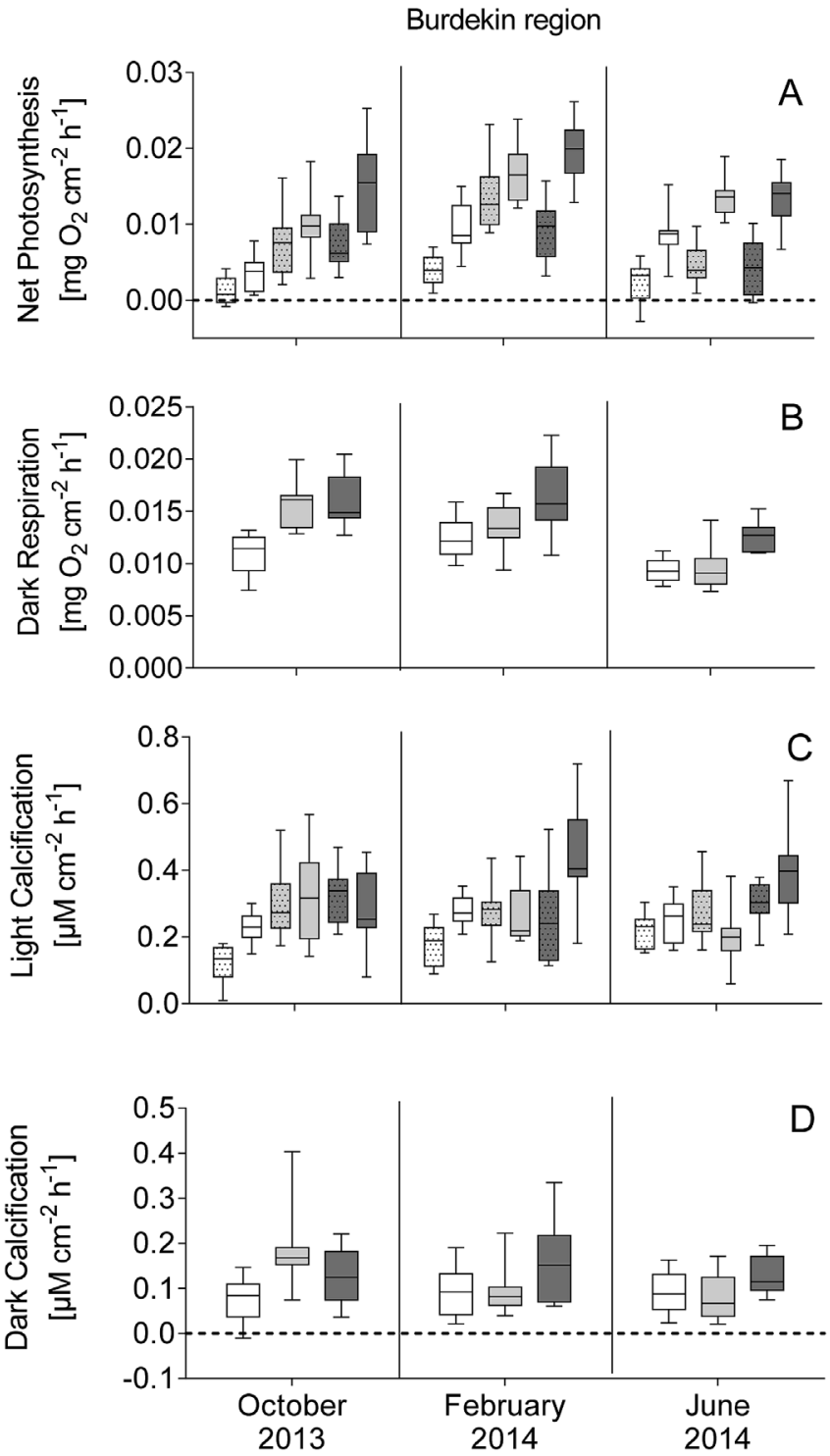

Fig. 2. Physiological performance of Acropora tenuis at three inshore reefs in the Burdekin region (white box $=$ Pelorus, very good water quality; light grey box $=$ Pandora, good water quality; dark grey box = Magnetic Island, moderate water quality) during three sampling months; light measurements (A, C) conducted at low DLI (7.92-9.36 mol photons $\mathrm{m}^{-2} \mathrm{~d}^{-1}$, dotted boxes) and moderate DLI (13.86-16.38 mol photons $\mathrm{m}^{-2} \mathrm{~d}^{-1}$, plain boxes); $n=9-12$ per reef, month and parameter. ANOVA (of data set A, C) and GLM (of data set B, D) results are given in Table 2.

mouth. Meanwhile, corals showed no differences in physiological performance between Whitsundays reefs along the weaker water quality gradient. This is in agreement with recent studies describing a higher level of temporal and spatial variation in coral health and biochemical attributes in the Burdekin compared to the Whitsunday region (Rocker et al. 2017, 2019). Biochemical parameters in the same A. tenuis colonies along the weak water quality gradient investigated by Rocker and colleagues did not show clear differences related to turbidity; e.g. neither skeletal density nor energy storage indices were affected by distance from the river source (Rocker et al. 2017, 2019). This may be due to closer geographical distance (30 versus $65 \mathrm{~km}$ ), shorter spatial and environmental gradients and weaker site separation by water quality among the reefs in the Whitsunday compared to the Burdekin region (Table 1, Fabricius et al., 2013b; Rocker et al., 2017; Thompson et al., 2014a). Nevertheless, temperature seems to be an environmental factor driving physiological processes in corals at all six reefs. Dark
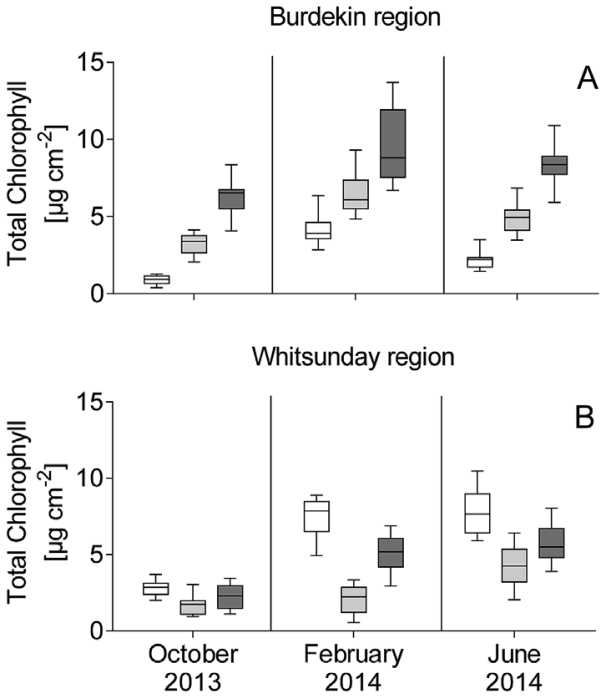

Fig. 3. Total chlorophyll content of Acropora tenuis at six inshore reefs of the Great Barrier Reef in the Burdekin region (A: white box = Pelorus, very good water quality; light grey box = Pandora, good water quality; dark grey box = Magnetic Island, moderate water quality) and the Whitsunday region (B: white box = Double Cone, good water quality; light grey box = Day Dream, moderate water quality; dark grey box = Pine, poor water quality) during three sampling months; mean $\pm \mathrm{SD}, n=9-12$ per reef and month. ANOVA results are given in Tables 2 and 4 .

respiration rates in $A$. tenuis in the Burdekin and Whitsunday region were lowest in June with lowest average seawater temperatures of $22^{\circ} \mathrm{C}$ compared to $27-30{ }^{\circ} \mathrm{C}$ in February. Highest photosynthesis rates were found in corals at all reefs in summer (= February), which is according to the general temperature dependence of physiological processes in marine invertebrates (Newell, 1970). Several coral studies attributed seasonal changes in standard metabolic rate, photosynthesis and calcification rates mainly to differences in temperature, but also to light level and food availability (Buckley and Szmant, 2004; Ferrier-Pagès et al., 2003).

\subsection{Acclimation potential of shallow water corals to marginal reef conditions in the Burdekin region}

Contrary to the expectations, most physiological and biochemical parameters investigated in A. tenuis (this study, Rocker et al., 2017, and Rocker et al., 2019) correlated negatively with water quality and distance from the river mouth in the Burdekin region at moderate (DLI $=13.86-16.38 \mathrm{~mol}$ photons $\mathrm{m}^{-2} \mathrm{~d}^{-1}$ ) but not low light conditions. At moderate light, biochemical and physiological health parameters suggested strongest performance in A. tenuis from the lowest water quality site in the Burdekin region (this study and Rocker et al., 2017). At Magnetic Island, calculated DLI at $2 \mathrm{~m}$ depth where the coral racks were located, was up to $48 \%$ lower compared to the other two reefs throughout the year. The high growth rates at this site suggest a high potential for acclimation to marginal light conditions and increasing nutrients and turbidity in corals on the upper reef slopes, possibly by improved photosynthetic efficiency. Indeed, total chlorophyll content, net photosynthesis and light and net calcification were highest in corals at Magnetic Island at moderate light in February (this study and Rocker et al., 2017). Also, symbiont densities were highest at the most turbid reef, and dominated by Symbiodinium type $\mathrm{C} 1$, which are typically more common at inshore sites (Rocker et al., 2017, Ulstrup and Van Oppen, 2003). This indicates an optimisation of the light harvesting function in response to light attenuation and suggests that in-water light levels are key drivers of spatial variation in coral pigmentation and physiological performance. In agreement, previous field 
Table 2

Differences in physiological parameters in Acropora tenuis in the Burdekin region between three inshore reefs, three seasons ('month') and with experimental light levels. Significant differences $(P<0.05)$ of ANOVA (dark respiration and calcification, chlorophyll Total $_{\text {) }}$ or GLM (net photosynthesis, light and net calcification) results are highlighted in bold. DF $=$ degrees of freedom.

\begin{tabular}{|c|c|c|c|}
\hline & $\mathrm{DF}$ & $\mathrm{F}$ & $\mathrm{P}$ \\
\hline \multicolumn{4}{|l|}{ Net Photosynthesis } \\
\hline Light & 1 & 133.9 & $<0.001$ \\
\hline Month & 2 & 48.2 & $<0.001$ \\
\hline Reef & 2 & 0.4 & 0.658 \\
\hline Light:Month & 2 & 10.3 & $<0.001$ \\
\hline Light:Reef & 2 & 3.9 & 0.021 \\
\hline Residuals & 199 & & \\
\hline \multicolumn{4}{|l|}{ Dark Respiration } \\
\hline Month & 2 & 30.6 & $<0.001$ \\
\hline Reef & 2 & 27.1 & $<0.001$ \\
\hline Month:Reef & 4 & 4.0 & 0.007 \\
\hline Residuals & 89 & & \\
\hline \multicolumn{4}{|l|}{ Light Calcification } \\
\hline Light & 1 & 0.2 & 0.656 \\
\hline Month & 2 & 2.3 & 0.106 \\
\hline Reef & 2 & 7.1 & 0.001 \\
\hline Light:Month & 2 & 2.5 & 0.084 \\
\hline Light:Reef & 2 & 4.2 & 0.016 \\
\hline Month:Reef & 4 & 2.7 & 0.035 \\
\hline Light:Month:Reef & 4 & 3.4 & 0.011 \\
\hline Residuals & 195 & & \\
\hline \multicolumn{4}{|l|}{ Dark Calcification } \\
\hline Month & 2 & 1.4 & 0.252 \\
\hline Reef & 2 & 5.9 & 0.004 \\
\hline Month:Reef & 4 & 4.4 & 0.003 \\
\hline Residuals & 87 & & \\
\hline \multicolumn{4}{|l|}{ Net calcification } \\
\hline Light & 1 & 5.1 & 0.025 \\
\hline Month & 2 & 2.5 & 0.089 \\
\hline Reef & 2 & 21.0 & $<0.001$ \\
\hline Light:Month & 2 & 1.9 & 0.155 \\
\hline Light:Reef & 2 & 3.0 & 0.055 \\
\hline Month:Reef & 4 & 6.2 & $<0.001$ \\
\hline Residuals & 185 & & \\
\hline \multicolumn{4}{|l|}{ Chlorophyll $_{\text {Total }}$} \\
\hline Month & 2 & 55.4 & $<0.001$ \\
\hline Reef & 2 & 172.6 & $<0.001$ \\
\hline Month:Reef & 4 & 0.4 & 0.810 \\
\hline Residuals & 91 & & \\
\hline
\end{tabular}

Table 3

Calculated net calcification rates $\left(\mu \mathrm{M} \mathrm{cm}{ }^{-2} \mathrm{~h}^{-1}\right)$ in Acropora tenuis at six inshore reefs of the Great Barrier Reef, during three months and at low DLI (7.92-9.36 mol photons $\mathrm{m}^{-2} \mathrm{~d}^{-1}$ ) and moderate DLI (13.86-16.38 mol photons $\mathrm{m}^{-2} \mathrm{~d}^{-1}$ ); mean $\pm \mathrm{SD}, n=9-12$ per reef and month. ANOVA (Whitsunday region) and GLM results (Burdekin region) are given in Tables 2 and 4.

\begin{tabular}{|c|c|c|c|}
\hline & October 2013 & February 2014 & June 2014 \\
\hline \multicolumn{4}{|c|}{ Burdekin region, moderate $D L I$} \\
\hline Pelorus & $3.71 \pm 0.94$ & $4.65 \pm 0.82$ & $4.06 \pm 1.22$ \\
\hline Pandora & $6.00 \pm 2.47$ & $4.55 \pm 1.71$ & $3.26 \pm 1.60$ \\
\hline Magnetic Island & $4.83 \pm 1.85$ & $7.50 \pm 2.86$ & $6.12 \pm 1.62$ \\
\hline \multicolumn{4}{|c|}{ Burdekin region, low DLI } \\
\hline Pelorus & $2.21 \pm 1.17$ & $3.37 \pm 1.35$ & $3.62 \pm 1.06$ \\
\hline Pandora & $5.66 \pm 2.07$ & $4.60 \pm 1.45$ & $3.97 \pm 1.67$ \\
\hline Magnetic Island & $5.52 \pm 1.61$ & $5.07 \pm 2.70$ & $5.08 \pm 0.98$ \\
\hline \multicolumn{4}{|c|}{ Whitsunday region, moderate DLI } \\
\hline Double Cone & $3.57 \pm 1.33$ & $4.51 \pm 1.75$ & $3.60 \pm 1.02$ \\
\hline Daydream & $4.18 \pm 2.10$ & $4.48 \pm 1.44$ & $3.78 \pm 1.67$ \\
\hline Pine & $2.82 \pm 2.50$ & $4.64 \pm 1.87$ & $4.20 \pm 1.00$ \\
\hline
\end{tabular}

Table 4

Differences in physiological parameters in Acropora tenuis in the Whitsunday region between three inshore reefs and three seasons ('month'). Significant differences (ANOVA, $\mathrm{P}<0.05$ ) are highlighted in bold. DF $=$ degrees of freedom.

\begin{tabular}{|c|c|c|c|}
\hline & DF & $\mathrm{F}$ & $\mathrm{P}$ \\
\hline \multicolumn{4}{|c|}{ Net Photosynthesis } \\
\hline Month & 2 & 54.7 & $<0.001$ \\
\hline Reef & 2 & 2.5 & 0.089 \\
\hline Month:Reef & 4 & 1.1 & 0.373 \\
\hline Residuals & 91 & & \\
\hline \multicolumn{4}{|c|}{ Dark Respiration } \\
\hline Month & 2 & 17.2 & $<0.001$ \\
\hline Reef & 2 & 2.9 & 0.058 \\
\hline Month:Reef & 4 & 1.7 & 0.155 \\
\hline Residuals & 92 & & \\
\hline \multicolumn{4}{|c|}{ Light Calcification } \\
\hline Month & 2 & 0.6 & 0.553 \\
\hline Reef & 2 & 0.1 & 0.996 \\
\hline Month:Reef & 4 & 0.9 & 0.489 \\
\hline Residuals & 91 & & \\
\hline \multicolumn{4}{|c|}{ Dark Calcification } \\
\hline Month & 2 & 1.6 & 0.211 \\
\hline Reef & 2 & 1.3 & 0.291 \\
\hline Month:Reef & 4 & 0.5 & 0.752 \\
\hline Residuals & 92 & & \\
\hline \multicolumn{4}{|c|}{ Net calcification } \\
\hline Month & 2 & 2.3 & 0.105 \\
\hline Reef & 2 & 0.2 & 0.820 \\
\hline Month:Reef & 4 & 0.4 & 0.803 \\
\hline Residuals & 87 & & \\
\hline \multicolumn{4}{|c|}{ Chlorophyll $_{\text {Total }}$} \\
\hline Month & 2 & 93.9 & $<0.001$ \\
\hline Reef & 2 & 56.1 & $<0.001$ \\
\hline Month:Reef & 4 & 5.5 & $<0.001$ \\
\hline Residuals & 93 & & \\
\hline
\end{tabular}

studies in inshore reefs of the GBR and around Singapore found increasing coral chlorophyll concentrations as light level decline (Browne et al., 2015; Cooper et al., 2008). During a one-year-time series at three reefs around Singapore, two foliose corals (Merulina ampliata and $\mathrm{Pa}$ chyseris speciosa) and one branching coral (Pocillopora damicornis) showed highest chlorophyll $a$ concentrations and maximum quantum yields ( Fv/Fm) at the site with the lowest light levels and highest sediment load and nutrient concentrations (Browne et al., 2015).

On the other hand, highest metabolic rates $(=$ dark respiration rates) in A. tenuis at Magnetic Island in the present study point towards intensified heterotrophic feeding and oxidation processes to metabolise food components. This is supported by high contents of $n-6$ polyunsaturated fatty acids (PUFA) in corals at Magnetic Island (Rocker et al., 2019), in conjunction with high levels of n-6 PUFA in the food chain within the Queensland region (Armstrong et al., 1994). In agreement, previous field and laboratory studies found high respiration rates in corals exposed to suspended sediments/particulate matter and light shading due to increasing particle feeding and sediment rejection activity (Abdel-Salam and Porter, 1988; Anthony and Fabricius, 2000; Yentsch et al., 2002). The ability to shift from autotrophy to heterotrophy is an important strategy to support the energy requirements of corals at reduced light but high nutrient availability (Anthony and Fabricius, 2000; Hinrichs et al., 2013). At $2 \mathrm{~m}$ depth, A. tenuis showed two times higher growth rates at Magnetic Island and Pandora compared to Pelorus and highest contents of ash free dry weight (as a marker for organic content) and lipids (as a marker for energy storage), despite lowest water quality at Magnetic Island (Rocker et al., 2017). Here, seawater concentrations in total particulates and total suspended 

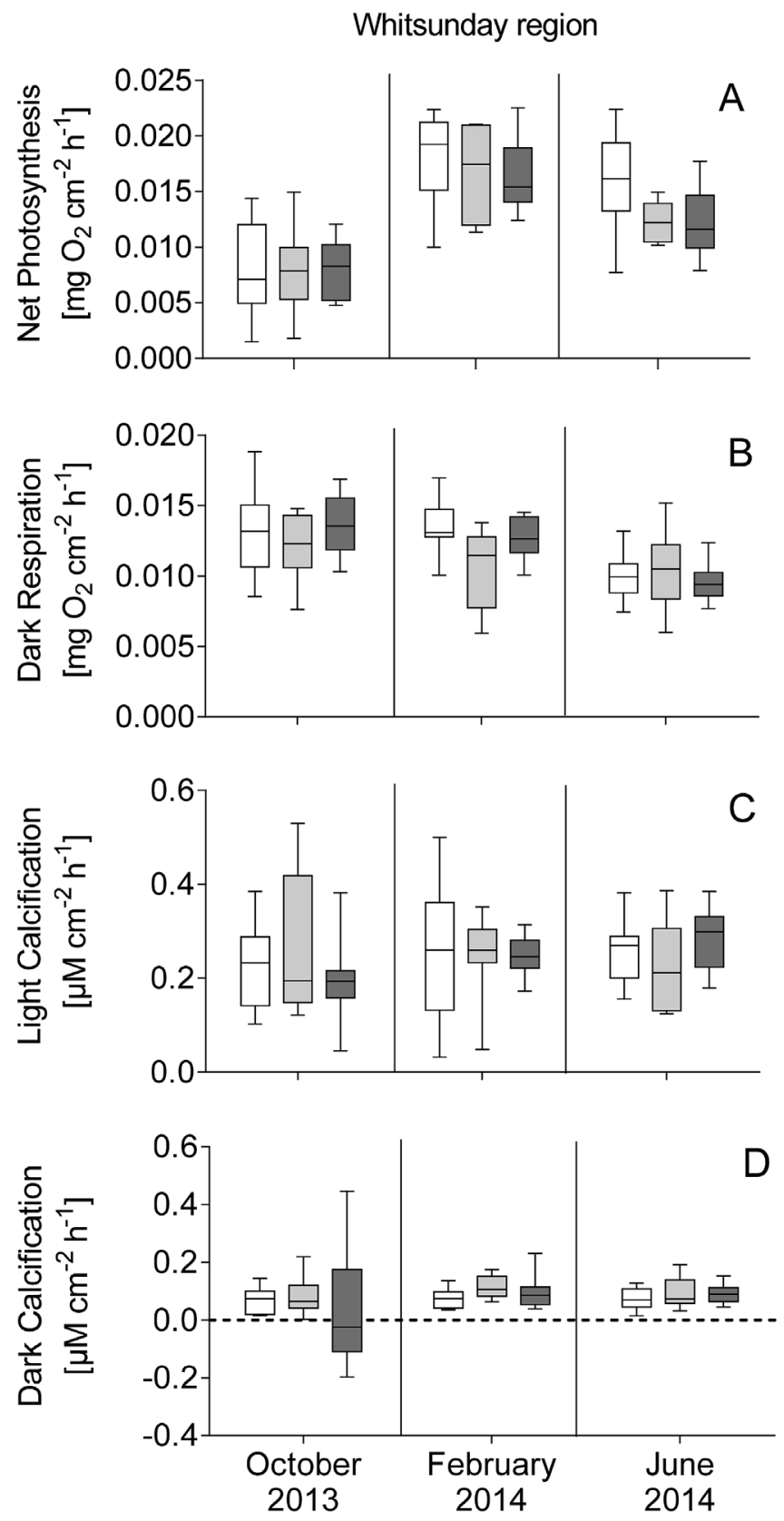

Fig. 4. Physiological performance of Acropora tenuis at three inshore reefs in the Whitsunday region (white box = Double Cone, good water quality; light grey box = Day Dream, moderate water quality; dark grey box = Pine, poor water quality) during three sampling months; light measurements (A, C) conducted at moderate DLI (13.86-16.38 mol photons $\mathrm{m}^{-2} \mathrm{~d}^{-1}$ ); $n=9-12$ per reef, month and parameter. ANOVA results are given in Table 4.

solids were higher than at the other two reefs in the Burdekin region during all three months, some of which can act as supplemental food source in corals (Anthony and Fabricius, 2000). Higher lipid contents in A. tenuis were also found at inshore compared to offshore reefs (Anthony, 2006), suggesting that corals have acclimatised to marginal water quality conditions in Cleveland Bay (Browne, 2012), at least in very shallow water and at moderate DLI.

4.3. Prolonged or frequently low DLI will reduce physiological performance in corals at inshore reefs

Our incubation data at low DLI (7.92-9.36 mol photons $\mathrm{m}^{-2} \mathrm{~d}^{-1}$ ) support earlier studies stating that light variability from sediment resuspension will affect the autotrophic energy balance and the resilience of some corals in coastal reefs, due to their limited capacity to photoacclimate (Bessell-Browne et al., 2017a; Di Perna et al., 2018; Richmond, 1993). An experimental light reduction of $\sim 43 \%$ from moderate to low DLI - the latter being in the range of mean irradiances measured from 2005 to 2007 at Magnetic Island at $3.5 \mathrm{~m}$ depth (Cooper et al., 2008) and in June and October 2007-2014 at Magnetic Island and the Whitsundays at $5 \mathrm{~m}$ depth (this study)- considerable reduced net photosynthetic, light and net calcification rates in corals at all three reefs in the Burdekin region. This indicates that the potential of $A$. tenuis to optimize photosynthesis at marginal DLI (see paragraph 4.2) seems to be reduced at low DLI. The ability to photoacclimate to variable light intensities, either morphologically (e.g. adjustment of growth forms) or physiologically (e.g. adjustments of the photosynthetic apparatus to increase the photosynthetic potential or the maximum quantum yield of photosystem II) can be highly species specific (Browne et al., 2014; Di Perna et al., 2018). Ideally, corals from low light habitats have increased light-absorption capacities, higher light-harvesting pigment contents and higher photochemical efficiencies (Dubinsky et al., 1984; Hennige et al., 2008). A recent experimental study showed fast photoacclimation at a time scale of 3-5 days in the shade-tolerant coral Pachyseris speciose with rapid declines in maximum quantum yield during high light ( $32 \mathrm{~mol}$ photons $\mathrm{m}^{-2} \mathrm{~d}^{-1}$ ) and subsequent recoveries during low light ( $6 \mathrm{~mol}$ photons $\mathrm{m}^{-2} \mathrm{~d}^{-1}$ ) (Di Perna et al., 2018). In contrast, shallow-water Acropora millepora were unable to rapidly adjust their photophysiology to variable light, and had slow ( $>20$ days) photoacclimation and minimal changes in photosynthetic yields (Di Perna et al., 2018). This resulted in limited oxygen production under both low and variable DLI, which is consistent with our findings of reduced net photosynthesis rates in A. tenuis at low DLI. Similarly, the capacity for short-term ( 9 days) photoacclimation to variable experimental light level was limited in four Acropora species (Langlois and Hoogenboom, 2014). These studies suggest, that rapid (within days) and prolonged (for several days or weeks) declines in DLI to $<13 \mathrm{~mol}$ photons $\mathrm{m}^{-2} \mathrm{~d}^{-1}$ due to high levels of terrestrial run-off and sediment re-suspension might induce physiological stress in A. millepora and other inshore corals with limited capacities for photoacclimation. In coastal shallow water environments, variable clouds and turbidity can alter the cumulative amount of light a benthic organism receives up to five-fold from one day to the next (Anthony et al., 2007), on top of seasonal changes due to varying day length and sun angle (Gattuso et al., 2006). Strong daily and weekly variability in turbidity of more than 8-16-fold due to changing waves, tides, river flow and rainfall also suggest rapid changes in DLI in these regions (Fabricius et al., 2013a). And predicted intensification of rainfall variability due to increasing greenhouse gas concentrations (Lough, 2011) might increase the frequency of extremely low DLI events in already turbid inshore reefs of the GBR.

Rocker et al. (2017) studied different biochemical and morphological parameters in the same $A$. tenuis colonies at the same sampling times. They found reduced skeletal densities in colonies at Magnetic Island and Pandora compared to Pelorus in 2012-2014, probably as a result of limited photoacclimation. It has been reported previously that corals produce fragile thin skeletons under reduced light conditions (Cook et al., 1997). This effect, which was observed in the Burdekin region during two-years of relatively benign environmental conditions without extreme events (e.g. no anomalously warm summer temperature, decreased salinity, heavy rainfall or extensive run-offs), could intensify in years of above-median rainfall and seasonal flooding. While the skeletal framework extends during dark calcification by growing randomly-oriented granular crystals, this framework is filled in during light calcification (Gladfelter, 1983). Thus, low light availability over extended periods of time might severely limit light calcification, while the much smaller dark calcification will remain unaffected. Indeed, in the present study light calcification of $A$. tenuis at Magnetic Island decreased up to $42 \%$ at low compared to moderate DLI. This, in turn, 
might have led to greater skeletal extension than infilling rates in corals at the most turbid reef site, resulting in a reduced skeletal density and a compromised structural integrity (Rocker et al., 2017). Calcification rates were also consistently low in three corals species ( $A$. formosa, Montipora aeqituberculata, Turbinaria mesenterina) at Middle reef off Magnetic Island in 1-3 $\mathrm{m}$ depths, when light was reduced to $<50 \%$ of the light available at the surface (Browne, 2012). And other studies showed that prolonged periods of light limitation and reduced photosynthesis can lead to a negative energy balance, and reduce growth and survival in corals (Bessell-Browne et al., 2017a; Richmond, 1993). During a 4-week aquarium experiment, light attenuation alone or in combination with elevated suspended solid concentrations (SSC) increased mortality rates in three scleractinian corals (Acropora millepora, Montipora capricornis, Porites spp.) (Bessell-Browne et al., 2017a).

Light attenuation might also be a key driver limiting depth distributions of $A$. tenuis and other corals in turbid inshore reefs with a reduced photoacclimation capacity to frequently low DLI. Longer times of high turbidity and sediment re-suspension (> $50 \mathrm{mg}$ suspended sediment $1^{-1}$ ) are not rare in the central inshore GBR (Cooper et al., 2008), which might reduce the physiological fitness and resilience of corals at depths below 2-3 m. E.g. during a 2-year time series at Magnetic Island, mean total daily benthic irradiances at around $3.5 \mathrm{~m}$ depth were reduced to $5.8 \pm 0.9 \mathrm{~mol}$ photons $\mathrm{m}^{-2}$ day $^{-1}$ during a 4-week turbidity event in March/April 2007 and to $1.3 \pm 0.5 \mathrm{~mol}$ photons $\mathrm{m}^{-2}$ day $^{-1}$ over 10 days of very strong winds (Cooper et al., 2008). And in the present study, corals received on average $51 \%$ of surface DLI at $2 \mathrm{~m}$ depth and only $22 \%$ at $5 \mathrm{~m}$, averaged across all 6 sites and sampling months. This demonstrates the potential stress increase associated with light reduction within the first $5 \mathrm{~m}$ in inshore reefs, especially at Magnetic Island and in the Whitsunday region, where calculated DLI at $5 \mathrm{~m}$ depth was on average $48 \%$ lower compared to Pelorus and Pandora (Table 1). Thompson et al. (2014b) found a reduction in coral density and changes in assemblage composition of juveniles in the Whitsunday region during a six-year period (2007-2012) of above-median rainfall and seasonal flooding and compared to a fiveyear period (2002-2006) of below median rainfall. In the same period, Acropora showed a consistent decline in coral cover and juvenile abundance over 10 years (2002-2012), which was more pronounced at $5 \mathrm{~m}$ than at $2 \mathrm{~m}$ depth and is consistent with the compounding of reduced light availability and increased sedimentation with increasing depth (Thompson et al., 2014b; Wolanski et al., 2005). In future research it would be interesting to study physiological mechanisms underlying this threshold of acclimation potential to the combined effects of light reduction (low DLI), sedimentation and increased nutrients in inshore corals growing at different depths between $2 \mathrm{~m}$ and $5 \mathrm{~m}$ and with previous exposure to increasing levels of light attenuation.

\subsection{Conclusions}

The present and recent studies showed that the observed variation in water quality did not have detrimental effects on A. tenuis in shallow waters of $\sim 2 \mathrm{~m}$ depth as long as light is not limiting. Low water quality only affected skeletal density, which decreased as linear extension increased (Rocker at al. 2017). It remains unclear how corals will respond during extreme weather events, especially in greater depths at the more turbid reefs in the inshore GBR, and with respect to the predicted intensification of rainfall variability due to increasing greenhouse gas concentrations. Our incubation data suggest that prolonged or frequently low light availability will affect the autotrophic energy balance and calcification in corals, and that light limitation might be a key driver limiting coral depth distributions in turbid inshore reefs. Therefore, benthic irradiance rather than turbidity is likely to be a good predictor of ecosystem health, especially in the context of globally increasing exposure of coral reefs to coastal run-off and decreasing water quality.

\section{Author contribution statement}

J. S. and K. E. F. developed the experimental design and concept. J. S. and M. M. R conducted the experiments. J.S. prepared the first draft for the manuscript, which was reviewed and improved by all authors.

\section{Conflicts of interest}

We declare we have no competing interests.

\section{Acknowledgements}

We thank B. Schaffelke, A. Thompson, S. Noonan, M. Skuza and the MMP team for logistical and field support, and A. Carion and I. Stolz for field and laboratory support. Many thanks to M. Kebben, N. Jeeves and G. Brinkman at the AIMS Workshop for building the incubation setup, and to J. N. Smith for the support in data analysis. Laboratory facilities at the Australian Institute of Marine Science were used for this study. The Great Barrier Reef Marine Park Authority provided Research Permit No. G35406.1. This project was funded by the Australian Government's Super Science Initiative (Grant FS110200034), the Australian Government's National Environmental Research Program and National Environmental Science Program - Tropical Ecosystems Hub, the PADI Grant Foundation, the ARC Centre of Excellence for Coral Reef Studies (Grant No. CEO561435 (2012-2013) and CE140100020 (2014-2016)), and the Australian Institute of Marine Science.

\section{References}

Abdel-Salam, H.A., Porter, J.W., 1988. Physiological effects of sediment rejection on photosynthesis and respiration in three Caribbean reef corals. In: Proceedings of the 6th International Coral Reef Symposium, Australia, vol. 2. pp. 285-292.

Anthony, K.R.N., 2006. Enhanced energy status of corals on coastal, high-turbidity reefs. Mar. Ecol. Prog. Ser. 319, 111-116.

Anthony, K.R.N., Fabricius, K.E., 2000. Shifting roles of heterotrophy and autotrophy in coral energetics under varying turbidity. J. Exp. Biol. Ecol. 252, 221-253.

Anthony, K.R.N., Connolly, S.R., 2004. Environmental limits to growth: physiological niche boundaries of corals along turbidity-light gradients. Oecologia 141, 373-384.

Anthony, K.R.N., Connolly, S.R., Hoegh-Guldberg, O., 2007. Bleaching, energetics, and coral mortality risk: effects of temperature, light, and sediment regime. Limnol. Oceanogr. 52, 716-726.

Armstrong, S.G., Wyllie, S.G., Leach, D.N., 1994. Effects of season and location of catch on the fatty acid compositions of some Australian fish species. Food Chem. 51, 295-305.

Bainbridge, Z.T., Wolanski, E., Álvarez-Romero, J.G., Lewis, S.E., Brodie, J.E., 2012. Fine sediment and nutrient dynamics related to particle size and floc formation in a Burdekin River flood plume, Australia. Mar. Pollut. Bull. 65, 236-248.

Bessell-Browne, P., Negri, A.P., Fisher, R., Clode, P.L., Duckworth, A., Jones, R., 2017a Impacts of turbidity on corals: the relative importance of light limitation and suspended sediments. Mar. Pollut. Bull. 117, 161-170.

Bessell-Browne, P., Negri, A.P., Fisher, R., Clode, P.L., Jones, R., 2017b. Impacts of light limitation on corals and crustose coralline algae. Sci. Rep. 7 (1), 11553.

Bradshaw, A.D., 1965. Evolutionary significance of phenotypic plasticity in plants. Adv. Genet. 115-155 Elsevier.

Brodie, J.E., McKergow, L.A., Prosser, I.P., Furnas, M., Hughes, A.O., Hunter, H., 2003. Sources of Sediment and Nutrient Exports to the Great Barrier Reef World Heritage Area. Australian Centre for Marine and Tropical Freshwater Research Report No 03/ 11. James Cook University, Townsville.

Browne, N.K., 2012. Spatial and temporal variations in coral growth on an inshore turbid reef subjected to multiple disturbances. Mar. Environ. Res. 77, 71-83.

Browne, N.K., Precht, E., Last, K.S., Todd, P.A., 2014. Photo-physiological costs associated with acute sediment stress events in three near-shore turbid water corals. Mar. Ecol Prog. Ser. 502, 129-143.

Browne, N.K., Tay, J.K.L., Low, J., Larson, O., Todd, P.A., 2015. Fluctuations in coral health of four common inshore reef corals in response to seasonal and anthropogenic changes in water quality. Mar. Environ. Res. 105, 39-52.

Buckley, B.A., Szmant, A.M., 2004. RNA/DNA ratios as indicators of metabolic activity in four species of Caribbean reef-building corals. Mar. Ecol. Prog. Ser. 282, 143-149.

Chisholm, J.R.M., Gattuso, J.P., 1991. Validation of the alkalinity anomaly technique for investigating calcification and photosynthesis in coral-reef communities. Limnol. Oceanogr. 36, 1232-1239.

Cook, C., Mueller, E., Ferrier, M., 1997. Special Studies in the Florida Keys National Marine Sanctuary Final Report for the USEPA. South Florida Water Management District.

Cooper, T.F., Ridd, P.V., Ulstrup, K.E., Humphrey, C., Slivkoff, M., Fabricius, K.E., 2008. Temporal dynamics in coral bioindicators for water quality on coastal coral reefs of 
the Great Barrier Reef. Mar. Freshw. Res. 59, 703-716.

Di Perna, S., Hoogenboom, M., Noonan, S., Fabricius, K.E., 2018. Effects of variability in daily light integrals on the photophysiology of the corals Pachyseris speciosa and Acropora millepora. PLoS One 13, e0203882.

Dubinsky, Z., Falkowski, P., Porter, J., Muscatine, L., 1984. Absorption and utilization of radiant energy by light-and shade-adapted colonies of the hermatypic coral Stylophora pistillata. Proc. R. Soc. Lond. Ser. B Biol. Sci. 222, 203-214.

Erftemeijer, P.L., Riegl, B., Hoeksema, B.W., Todd, P.A., 2012. Environmental impacts of dredging and other sediment disturbances on corals: a review. Mar. Pollut. Bull. 64, 1737-1765.

Fabricius, K.E., Cséke, S., Humphrey, C., De’ath, G., 2013a. Does trophic status enhance or reduce the thermal tolerance of scleractinian corals? A review, experiment and conceptual framework. PLoS One 8, e54399.

Fabricius, K.E., De'ath, G., Humphrey, C., Zagorskis, I., Schaffelke, B., 2013b. Intra-annual variation in turbidity in response to terrestrial runoff on near-shore coral reefs of the Great Barrier Reef. Estuar. Coast. Shelf Sci. 116, 57-65.

Ferrier-Pagès, C., Rottier, C., Beraud, E., Levy, O., 2010. Experimental assessment of the feeding effort of three scleractinian coral species during a thermal stress: effect on the rates of photosynthesis. J. Exp. Mar. Biol. Ecol. 390, 118-124.

Ferrier-Pagès, C., Witting, J., Tambutté, E., Sebens, K., 2003. Effect of natural zooplankton feeding on the tissue and skeletal growth of the scleractinian coral Stylophora pistillata. Coral Reefs 22, 229-240.

Fuessel, H.-M., 2009. An updated assessment of the risks from climate change based on research published since the IPCC Fourth Assessment Report. Clim. Change 97, 469.

Gattuso, J.-P., Gentili, B., Duarte, C.M., Kleypas, J., Middelburg, J.J., Antoine, D., 2006. Light availability in the coastal ocean: impact on the distribution of benthic photosynthetic organisms and contribution to primary production. Biogeosci. Discuss. 3, 895-959.

Gladfelter, E.H., 1983. Skeletal development in Acropora cervicornis. Coral Reefs 2, 91-100.

Grottoli, A.G., Rodrigues, L.J., Juarez, C., 2004. Lipids and stable carbon isotopes in two species of Hawaiian corals, Porites compressa and Montipora verrucosa, following a bleaching event. Mar. Biol. 145, 621-631.

Hennige, S.J., Smith, D.J., Perkins, R., Consalvey, M., Paterson, D.M., Suggett, D.J., 2008. Photoacclimation, growth and distribution of massive coral species in clear and turbid waters. Mar. Ecol. Prog. Ser. 369, 77-88.

Hinrichs, S., Patten, N.L., Feng, M., Strickland, D., Waite, A.M., 2013. Which environmental factors predict seasonal variation in the coral health of Acropora digitifera and Acropora spicifera at Ningaloo Reef? PLoS One 8, e60830.

Howells, E.J., Berkelmans, R., van Oppen, M.J., Willis, B.L., Bay, L.K., 2013. Historical thermal regimes define limits to coral acclimatization. Ecology 94, 1078-1088.

Langlois, L.A., Hoogenboom, M.O., 2014. Capacity for short-term physiological acclimation to light does not control the lower depth distributions of branching corals. Mar. Ecol. Prog. Ser. 508, 149-162.

Lichtenthaler, H.K., 1987. Chlorophylls and carotenoids: pigments of photosynthetic biomembranes. Methods Enzymol. 148, 350-382.

Lough, J.M., 2011. Great Barrier Reef coral luminescence reveals rainfall variability over northeastern Australia since the 17th century. Paleoceanography 26 (2).

Loya, Y., Sakai, K., Yamazato, K., Nakano, Y., Sambali, H., van Woesik, R., 2001. Cora bleaching: the winners and the losers. Ecol. Lett. 4, 122-131.

Marshall, P., Baird, A., 2000. Bleaching of corals on the Great Barrier Reef: differential susceptibilities among taxa. Coral Reefs 19, 155-163.

McCulloch, M., Fallon, S., Wyndham, T., Hendy, E., Lough, J., Barnes, D., 2003. Coral record of increased sediment flux to the inner Great Barrier Reef since European settlement. Nature 421, 727.

Newell, R.C., 1970. Biology of Intertidal Animals.
Pollock, F.J., Lamb, J.B., Field, S.N., Heron, S.F., Schaffelke, B., Shedrawi, G., Bourne, D.G., Willis, B.L., 2014. Sediment and turbidity associated with offshore dredging increase coral disease prevalence on nearby reefs. PLoS One 9, e102498.

Richmond, R.H., 1993. Coral reefs: present problems and future concerns resulting from anthropogenic disturbance. Am. Zool. 33, 524-536.

Ritchie, R.J., 2008. Universal chlorophyll equations for estimating chlorophylls a, b, c, and $\mathrm{d}$ and total chlorophylls in natural assemblages of photosynthetic organisms using acetone, methanol, or ethanol solvents. Photosynthetica 46, 115-126.

Rocker, M.M., Francis, D.S., Fabricius, K.E., Willis, B.L., Bay, L.K., 2017. Variation in the health and biochemical condition of the coral Acropora tenuis along two water quality gradients on the Great Barrier Reef, Australia. Mar. Pollut. Bull. 119, 106-119.

Rocker, M.M., Francis, D.S., Fabricius, K.E., Willis, B.L., 2019. Temporal and spatia variation in fatty acid composition in Acropora tenuis corals along water quality gradients on the Great Barrier Reef, Australia. Coral Reefs. https://doi.org/10.1007/ s00338-019-01768-x.

Roff, G., Clark, T.R., Reymond, C.E., Zhao, J.X., Feng, Y., McCook, L.J., Done, T.J., Pandolfi, J.M., 2013. Palaeoecological evidence of a historical collapse of corals at Pelorus Island, inshore Great Barrier Reef, following European settlement. Proc. R. Soc. B 280, 2012-2100.

Schaffelke, B., Carleton, J., Skuza, M., Zagorskis, I, Furnas, M.J., 2012. Water quality in the inshore Great Barrier Reef lagoon: implications for long-term monitoring and management. Mar. Pollut. Bull. 65, 249-260.

Schlichting, C.D., 1986. The evolution of phenotypic plasticity in plants. Annu. Rev. Ecol. Systemat. 17, 667-693.

Stafford-Smith, 1993. Sediment-rejection efficiency of 22 species of Australian scleractinian corals. Mar. Biol. 115, 229-243.

Strahl, J., Stolz, I., Uthicke, S., Vogel, N., Noonan, S., Fabricius, K.E., 2015. Physiological and ecological performance differs in four coral taxa at volcanic carbon dioxide seeps. Comp. Biochem. Physiol., A 184, 179-186.

Thompson, A., Lønborg, C., Costello, P., Davidson, J., Logan, M., Furnas, M., Gunn, K., Liddy, M., Skuza, M., Uthicke, S., 2014a. Marine Monitoring Program: Annual Report of AIMS Activities 2013 to 2014. Inshore Water Quality and Coral Reef Monitoring (Report for the Great Barrier Reef Marine Park Authority).

Thompson, A., Schroeder, T., Brando, V.E., Schaffelke, B., 2014b. Coral community responses to declining water quality: Whitsunday Islands, Great Barrier Reef, Australia. Coral Reefs 33, 923-938.

Ulstrup, K.E., Van Oppen, M., 2003, Geographic and habitat partitioning of genetically distinct zooxanthellae (Symbiodinium) in Acropora corals on the Great Barrier Reef. Mol. Ecol. 12, 3477-3484.

Veal, C.J., Carmi, M., Fine, M., Hoegh-Goudberg, O., 2010. Increasing the accuracy of surface area estimation using single wax dipping of coral fragments. Coral Reefs 893-897.

Weber, M., De Beer, D., Lott, C., Polerecky, L., Kohls, K., Abed, R.M., Ferdelman, T.G., Fabricius, K.E., 2012. Mechanisms of damage to corals exposed to sedimentation. Proc. Natl. Acad. Sci. U.S.A. 109, E1558-E1567.

Wiedenmann, J., D'Angelo, C., Smith, E.G., Hunt, A.N., Legiret, F.-E., Postle, A.D. Achterberg, E.P., 2012. Nutrient enrichment can increase the susceptibility of reef corals to bleaching. Nat. Clim. Change 3, 160.

Wolanski, E., Fabricius, K.E., Spagnol, S., Brinkman, R., 2005. Fine sediment budget on an inner-shelf coral-fringed island, Great Barrier Reef of Australia. Estuar. Coast Shelf Sci. $65,153-158$.

Wooldridge, S.A., Done, T.J., 2009. Improved water quality can ameliorate effects of climate change on corals. Ecol. Appl. 19, 1492-1499.

Yentsch, C., Yentsch, C., Cullen, J., Lapointe, B., Phinney, D., Yentsch, S., 2002. Sunlight and water transparency: cornerstones in coral research. J. Exp. Mar. Biol. Ecol. 268, $171-183$. 